\title{
The Short Survey of ICT in Education in Japan
}

\section{FUJITA Takaaki ${ }^{\dagger 1}$}

\begin{abstract}
Information and Communication Technology (ICT) education has attracted attention in recent years. Despite the importance of the spread of the reason for this low spread rate is that there are many issues specific to ICT education such as monetary cost, time, environment, teacher education system, motivation, curriculum, and health problems. The reason for this low spread rate is that there are many issues specific to ICT education such as monetary cost, time, environment, teacher education system, motivation, curriculum, and health problems. In this paper, we investigated and considered the issues in ICT education from 10 viewpoints. In this paper, we investigated and considered the issues in ICT education in Japan from 10 viewpoints. There are a number of conclusions obtained in this paper. The main conclusions is as follows: (1)Monetary cost is the most important issue; (2)It is necessary to teach not only technology but also theory and common sense; The main conclusions are as follows: (1)Monetary cost is the most important issue; (2)It is necessary to teach not only technology but also theory and common sense; (3)It is necessary to urgently prepare an environment that requires ICT education after considering issues.
\end{abstract}

Keywords: ICT in education, ICT equipment, cost

\section{Introduction}

\subsection{Background of ICT education}

In recent years, the use of Information and Communication Technology (ICT) in education has been attracting attention. This ICT education refers to educational methods that utilize tablet terminals, IoT devices, electronic blackboards, and personal computers.

The Ministry of Education, Culture, Sports, Science and Technology (MEXT) has released the "White Paper on Education, Culture, Sports, Science and Technology (MEXT-White ${ }^{1)}$ Paper) for FY2008", which mentions the promotion of ICT utilization, for example, strengthening students' ability to use information and ICT, efforts for programming education, and ICT education for teachers. In addition, the Ministry of Education, Culture, Sports, Science and Technology's "Measures to Promote the Use of Advanced Technology to Support Learning in the New Era (2019) ${ }^{24) "}$ states that it will present a roadmap to realize the world's best ICT environment. In this way, the government is actively working on ICT education. In addition, the following advantages $\mathrm{can}^{21)}$ be obtained by actually implementing ICT education.

It is easy to motivate children.

- The educational effects of active learning can be easily obtained. 
- Children and students can learn what they want to learn at their own time.

- To be able to analyze the learning outcomes of children and adopt teaching methods that are appropriate for each individual.

- It is possible to automate some teaching tasks, such as grading tests.

- It can be a tool for parents to interactively communicate with teachers.

- Not only children, but also teachers can acquire ICT skills.

In addition to the above, there are many other advantages of ICT education. In addition, ICT education is an indispensable educational method in the global society, and ICT education is expected to expand more and more in the future. For these reasons, it is very important to promote ICT education and to conduct research on ICT education.

However, despite the importance of ICT education and the government's active efforts to promote it, the penetration rate of ICT equipment in educational settings is low. In the White ${ }^{1)}$ Paper on Education, Culture, Sports, Science and Technology, it is reported that only one learning computer is provided to every 5.6 children. In addition, the penetration rate of wireless LAN in classrooms is $34.5 \%$, and the rate of high speed Internet access is $91.8 \%$. Furthermore, there is a large disparity in these penetration rates, which the MEXT describes as a "critical situation". ${ }^{24)}$

We thought that the reason for the low penetration rate of ICT education was due to the many problems and disadvantages unique to ICT education, such as financial and time costs, the onsite environment, motivation, teachers' education system, and curriculum.

\subsection{Research Objectives of this Paper}

In this paper, barriers and challenges to ICT education and their solutions are investigated and discussed from various perspectives, including not only the issues that may occur when ICT equipment is introduced, but also the issues that may occur during the implementation and operation of ICT education. In this way, we will be able to sort out the issues in the current ICT education, which will have the merit of efficiently hedging the risks when actually introducing ICT equipment in the field.

\section{Issues in ICT education}

The primary reason for the lack of widespread adoption of ICT education is considered to be the financial and time costs. However, there are various other challenges to ICT education, and these challenges hinder the decision to introduce and operate ICT educational equipment. In this chapter, we discuss the disadvantages and challenges of ICT education from the following 10 perspectives. In this chapter, we discuss the disadvantages and challenges of ICT education from the following perspectives.

(1) Time and financial costs

(2) Views by teachers and parents

(3) Purchase, management, and operation of equipment and systems

(1) Equipment management

(2) Purchase of equipment 
(3) Other

(4) ICT education for teachers

(1) Technical Skills

(2) Other

(5) Lesson Content

(1) Curriculum

(2) What ICT education should aim for

(6) On-site environment

(7) Motivation of children

(8) health

(9) Cooperation with top management

(10) Clarification of vision

\subsection{Issues related to time and financial costs}

The main reason why ICT education cannot be introduced is the financial and time cost. First of all, this cost problem, especially the financial cost, needs to be solved as soon as possible. However, it is very difficult to provide tablet terminals and personal computers to all students (especially in rural schools) because it requires a large budget.

There are many references that discuss the financial and time costs. Some examples are shown below.

- Sasaki (2013) stated that in order to spread ICT education nationwide, it is necessary to reduce the financial cost ${ }^{14}$.

- Kobayashi et al. (2007) cited as a concern that it takes a lot of time to manage ICT devices ${ }^{8)}$.

- Kobayashi et al. () mentioned that it takes a lot of time to manage ICT devices as a concern. The details are described in Section 2.3.1.

- Takagi (2016) pointed out that teachers are very busy and cannot allocate much time and money $^{2)}$.

- Takagi (2016) argues that ICT education requires a huge budget and must be adopted by the legislature, resulting in a lack of suitable introduction methods in the educational field ${ }^{2)}$.

${ }^{25)}$ It is necessary to examine in detail whether the educational benefits of ICT education are commensurate with the financial costs2018.

In reality, no matter how motivated school teachers are to adopt ICT, the cost problem (especially the financial cost) is often unmanageable, and the government's active and continuous support is essential because the ICT environment often requires a large budget. This may be the reason why the government has been proactive in its policies. Examples are shown below.

- The Ministry of Education, Culture, Sports, Science and Technology (MEXT), in its "Trends in the Informatization of Education (2015)", has proposed support for reducing the financial cost and unit price of environmental improvements ${ }^{16)}$.

- The Ministry of Internal Affairs and Communications' Educational ICT Guidebook (2017) ${ }^{17)}$ encourages students to actively reduce their financial and time costs by using the cloud.

- The Ministry of Education, Culture, Sports, Science and Technology's "Measures to Promote 
the Use of Advanced Technology to Support Learning in the New Era (2019) 24)" presents a mode1 for developing an ICT environment without financial costs.

\subsection{Views of teachers and parents}

In the spread of ICT education, the attitudes of teachers and parents as well as the culture of the field can be barriers. For example, Toyofuku (2015) and Nemoto et al. (2016) pointed out the following problems ${ }^{7)}$, 13).

- For example, some teachers and parents believe that it is better to learn by handwriting instead of using ICT devices. For example, there are teachers and parents who believe that learning by handwriting instead of using ICT devices is better for children's humanity, that ICT devices have a negative impact on children's performance, or that children become dependent on ICT materials. These interpretations can be an obstacle to the introduction of ICT education. - The excessive demand for the effects of ICT education can be a barrier to its introduction. ICT education is not a magic that can produce overwhelming effects in an instant.

- If there are many teachers and parents who think that children will start playing with ICT devices when they use them, it will be an obstacle to the spread of ICT education.

The solutions to these problems include the following

- In this paper, I will explain the many advantages of ICT education to teachers and parents with old-fashioned ways of thinking. On the other hand, teach them that not everything can be done with ICT equipment.

- By giving teachers the opportunity to try out the ICT materials, they can change their way of thinking.

Although there are many papers that are positive about the spread of ICT, there are also some papers that are against the introduction of teaching materials using ICT devices ${ }^{23)}$. Urano et al. (2017) stated that the challenge is how to find a balance between traditional educational methods and ICT educational methods ${ }^{12)}$.

\section{3 I ssues in purchasing, managing, and operating equipment and systems}

Various problems also arise when purchasing, managing, and operating ICT equipment and educational support systems. These issues are also discussed in the "Measures to Promote the Use of Advanced Technology to Support Learning in the New Era (2019) 24)" prepared by the Ministry of Education, Culture, Sports, Science and Technology. Specifically, the following issues related to ICT equipment are listed.

- It is difficult to provide smooth education using video and remote control.

- The financial and time costs of maintaining, operating, and managing servers and networks.

- It is difficult for teachers alone to know which ICT equipment to install.

- The specifications of the ICT equipment to be introduced are unknown (the specifications of the introduced equipment are low).

- ICT equipment is very expensive. ICT equipment is very expensive compared to other equipment available in the market. 


\section{3.1 Issues related to the management of equipment and systems}

Matsunaga $(2011)^{5)}$ discusses the problems that arise when managing a large number of education-related systems. In some educational sites, systems for various purposes, such as personal computers for learning, tablet terminals, e-learning systems, and performance management systems, are operated using different management methods. In such cases, management becomes more difficult, and the time and management costs become enormous. Furthermore, in such an environment, security and privacy policies tend to be different for each system, and the management of IDs and passwords tends to be complicated.

The following are possible solutions to these problems.

A manual should be prepared to clarify the procedures for achieving the objectives, so that beginners and intermediate users can manage the system.

Do not try to solve the problem by yourself, but introduce new tools and systems. For example, use a password management tool that can manage passwords for all systems at once, or introduce a system that can monitor the status of all systems. Although there is still the issue of cost, there are free and inexpensive tools available, so it is a good idea to actively use them if possible (although many schools may not be able to introduce them due to various regulations). If the management of the systems becomes complicated, only the minimum number of systems should ${ }^{26)}$ be used.

\subsection{Problems with purchasing equipment and systems}

One of the problems is the inability to install the equipment and environment. This is mainly due to the financial cost, i.e., ICT equipment is very expensive. In addition, some equipment has a short service life and may need to be replaced every few years ${ }^{9), 25)}$.

The following are possible solutions to these problems.

As a temporary measure, it is possible to rent equipment instead of purchasing it, or to adjust the class time with other classes. Hara et al. (2018) ${ }^{4)}$ pointed out that ICT materials tend to be treated as supplementary materials. Therefore, for example, if the ICT materials are used only once out of two or three classes, it is possible to deal with this problem by renting equipment from other schools or private companies, or by staggering the class time with other classes to reduce the number of simultaneous use. However, this is not a fundamental solution. This method requires each family to purchase devices such as tablets and laptops. However, this method would increase the financial burden on families.

As mentioned in Chapter 2.1, the introduction of ICT equipment requires a large budget, so support from the government and local governments is essential. This financial support will lead to a fundamental solution.

\subsubsection{Other Issues}

Mitomo $(2018)^{19)}$ stated that a decrease in communication speed caused by inadequate network environment decreases the educational effect. As a countermeasure, it is suggested to reduce the number of simultaneous connections.

Mori $(2008)^{20)}$ argues that the e-learning system introduced in the university has become a system full of outdated information because few teachers are able to develop and update it. 
As a countermeasure, regular training should be provided.

The Ministry of Education, Culture, Sports, Science and Technology's "Measures to Promote the Use of Advanced Technology to Support Learning in the New Era (2019) ${ }^{24) " ~ m a d e ~ t h e ~ f o l l o w i n g ~}$ points regarding the use of data collected by ICT devices.

It has not been verified what kind of equipment is effective in utilizing the data.

The data collected by the instruments are not utilized in actual education.

It has not been considered in what situations the collected data can be used.

As a countermeasure, the Ministry of Education, Culture, Sports, Science and Technology (MEXT) has announced a policy to study the "standardization of educational data.

Other issues that need to be addressed include the following

The battery life of tablets and laptops is only about two to three hours, so they cannot be used continuously. ${ }^{9)}$ They must be recharged periodically.

Another problem is that there are few alternatives to tablets and laptops. As a countermeasure, it is suggested to prevent damage to the devices, for example, instructing children to take good care of them.

Hara et al. (2018) ${ }^{4)}$ cited copyright issues and differences in the use of ICT in different subjects as problems of ICT teaching materials. Hara et al. () cited copyright issues of teaching materials and differences in the use of ICT by subjects as problems of ICT teaching materials. However, since ICT has begun to be introduced in subjects such as physical ${ }^{3)}$ education and music ${ }^{15)}$, the differences in the use of ICT by subjects may be decreasing.

\subsection{Issues related to ICT education for teachers}

\subsubsection{Issues related to technology skills of teachers}

It is often argued that one of 1 the challenges of ICT education is that there are few teachers with the technical skills to handle ICT. Some concrete examples are shown below. According to Nemoto et al. $(2016)^{7)}$, one of the problems is that teachers do not know how to operate ICT devices, and cannot respond to unexpected behavior of the devices.

Hara et al. (2018) cited the occurrence of a digital divide among teachers as a problem ${ }^{4)}$. The Ministry of Education, Culture, Sports, Science and Technology's "Measures to Promote the Use of Advanced Technology to Support Learning in the New Era (2019) 24)" also points out the issue of teachers not knowing which ICT devices to install.

The following measures can be taken to address these issues.

The ICT education environment (group training environment and e-learning training environment) for teachers should be enhanced. However, teachers in the field are very busy, so there is a question of whether they will have time for training.

A manual is prepared so that even beginners can use the system.

To develop a user-friendly system that can be used by beginners.

In this paper, we will discuss the use of file sharing software to share knowledge among schools. Nagaoka et al. (2018) pointed out that the utilization rate of file-sharing software, which is a means of sharing knowledge among schools, is $1 \mathrm{ow}^{25)}$.

Create a system to ask questions to experts in case of emergency. 


\subsubsection{Other issues}

Even if we educate teachers on their skills, it will be of little use if the teachers are not motivated. This motivation for ICT education is also a problem.

Kobayashi et al. $(2007)^{8}$ argue that there are differences in ICT skills and motivation for ICT education among teachers. As a countermeasure, some kind of motivation (e.g., reward for success) is necessary.

Hara et al. (2018) also cited the digital divide among teachers as a problem ${ }^{4)}$. One possible solution is to actively hold training sessions for beginners.

\subsection{Issues related to class content}

\subsubsection{Curriculum-related issues}

In the actual implementation of ICT education, it will be necessary to change the contents of classes to be suitable for ICT education. Kobayashi et al. (2007) ${ }^{8)}$ argue that in order to make ICT education an important part of the school curriculum, it is necessary to change the curriculum drastically. This change in curriculum is a large time cost for teachers.

This suggests that there is a need for tools that can be used to easily improve class content in response to changes in the curriculum. For example, a visual programming tool such as Scratch. One of the strengths of Scratch is that it can be used to adjust the content of the programs taught to the students, in other words, the content of the class. In this sense, Microsoft Word and PowerPoint are also tools that can be used to improve the content of a class at any time. However, there are not many tools in the world that can be improved in this way. It is necessary to approach private companies that are good at developing such tools.

\subsubsection{What should be the goal of ICT education?}

Although this is a little off topic, I would like to consider the ideal form of ICT education in relation to the content of "information" classes in high school. Tachibana et al. (2012) ${ }^{6)}$ argue that the contents of "information" classes are too much focused on practical skills, in other words, technical training such as programming. There are two main things that should be done in information classes other than technical training.

To promote theoretical understanding of information. For example, in the case of programming education, education on algorithms and discrete mathematics. Through theoretical understanding, students can learn how to think in order to utilize technology.

To teach good sense to participate in the information society. With the spread of social network services such as Twitter, Facebook, and LINE, various problems such as leakage of personal information, slander, flaming, and prolonged use have occurred. In order to prevent students' behavior from triggering these problems, common sense is essential.

It is extremely difficult to train highly skilled teachers who can teach all 3 of the above mentioned skills, theory, and common sense. This is because there is a lack of technical skills education, such as programming education, for teachers before theory. There are only a few teachers who have technical skills, and it is very hard to ask busy teachers to have the skills to teach theory and common sense.

On the other hand, the author believes that the goal of information education is for both 
teachers and students to become human assets with a wide range of skills, theories, and common sense related to information and communication. In order for students to become human resources who can truly utilize information, they must have all three skills: technology, theory, and common sense.

We have discussed information education so far, and this is also true for ICT education. All school personnel, including teachers, students, parents, and staff, need to acquire the skills, theories, and common sense to use ICT, and this is the goal that ICT education should aim for.

\subsection{Challenges arising from the field environment}

There are also issues that arise due to the environment in the field. For example, Nemoto et al. $(2016)^{7)}$ pointed out that strict regulations in schools, such as security regulations and privacy regulations, are a concern for ICT education.

Such regulations are incompatible with the utilization of data that can be collected from ICT devices. The Ministry of Education, Culture, Sports, Science and Technology's "Measures to Promote the Use of Advanced Technology to Support Learning in the New Era201924)" points out that there is a poor balance between the use of data collected by ICT devices and ensuring security, i.e., too much attention is paid to security and privacy, and the use of data is not progressing.

In addition, Toyofuku (2015) ${ }^{13)}$ discusses the relationship between classroom teaching style and ICT education in the Japanese field. In Japan, one teacher basically teaches all children at the same time. However, Toyofuku (2015) argues that ICT education is more suitable for sma11-group classes than large-group classes ${ }^{13)}$. However, Toyofuku argues that ICT education is more suitable for small classes than for large classes, because the administrative costs for teachers are higher in large classes.

\subsection{Motivation of children and students}

The relationship between ICT education and the motivation of children and students is inseparable. No matter how well the environment is maintained, if the motivation of the students is low, the educational system will not be utilized.

Here are 2 some examples. Mori (2008) ${ }^{20)}$ argues that an e-learning system was introduced in a university, but it was hardly used due to low motivation of students. Mori et a1. (2015) 10) argued that in an experiment using an e-portfolio (ICT education), the following negative opinions were expressed by students.

- It takes extra time to learn.

- I feel that the learning place is far away.

- I don't feel that I have mastered the skills.

The following measures can be taken to address these motivations.

- To motivate children and students by reflecting the degree of their efforts in their grades.

- Create a system that allows students to use the system by incorporating it into the lecture curriculum.

- For learners who do not have a high level of autonomy, we wil122) use ICT systems to promote dialogue. 
- The teachers will actively follow up with the students who are not familiar with ICT devices. - Do not try to complete education only with ICT devices. Do not try to complete education with ICT devices alone. - Use ${ }^{12}$ a good balance between traditional education methods and education methods using ICT devices in the right places.

\subsection{Health challenges}

There are also concerns about health problems caused by ICT education. The Ministry of Education, Culture, Sports, Science and Technology's "Measures to Promote the Use of Advanced Technology to Support Learning in the New Era (2019) ${ }^{24) " ~ a l s o ~ c i t e s ~ i s s u e s ~ r e l a t e d ~ t o ~ h e a l t h . ~}$

One example of a specific concern is vision loss due to viewing screens of personal computers and tablet devices. Hashi et al. (2016) ${ }^{18)}$ stated that the increased use of personal computers, tablet computers, and electronic blackboards in ICT education will increase the burden on children with poor near vision. In addition, it is essential to take measures to prevent vision loss and to give consideration to children with poor near vision.

\subsection{Cooperation with top management}

Kobayashi et al. (2007) ${ }^{8)}$ argue that cooperation by top-level members is essential to promote ICT education in an organization. For this reason, direct negotiation with teachers is one of the ways. In addition, some local governments are ${ }^{11)}$ moving to develop human resources who can play a leading role in promoting ICT education.

\subsection{Clarification of vision}

Sasaki (2013) ${ }^{14)}$ argues that in order to spread ICT education, it is necessary to establish a vision for promoting the ICT environment. If we do not have a clear vision, we will just blindly introduce ICT devices and will not be able to expect educational effects.

\section{Conclusion.}

\subsection{Future tasks}

Future tasks for this paper include the following.

In addition to the issues in ICT education mentioned in this paper, new issues will be investigated by conducting a questionnaire survey of children and teachers in the educational field. In addition, we will examine whether the issues mentioned in this paper are really considered important in the field of education.

The papers discussed in this paper are only a few of the papers that deal with ICT education. We will conduct more multifaceted discussion and analysis by surveying more papers.

Many educational materials have been developed to teach technical skills in information. However, there are not many educational materials to develop theoretical understanding of information and common sense for handling information. Therefore, we will develop educational software for learning theory and common sense. 


\section{Acknowledgments}

I would like to express my sincere gratitude to all those who have supported me in completing this paper.

\section{References}

1), Ministry of Education, Culture, Sports, Science and Technology (2017), Education, Cultur e, Sports, Science and Technology White Paper, Chapter 11: Promoting the Use of ICT, availab le at: http://www. mext.go.jp/b_menu/hakusho/html/hpab201901/1420047_018.pdf, accessed Septem ber 29, 2019.

2) Ryo Takagi (2016), Issues of Educational Method in the Context of Current Educational Refo rm: Considering the Position of Educational Administration and Finance, Curriculum, and Teac hing Career, Journal of Graduate School of Education, 1 25-40.

3) Yokoo, T., Irie, Y., Goda, K., Xu, H., Tosaka, T., Mori, H., Sugama, Y. (2017), Practice of Health and Physical Education Class Using ICT, Bulletin of Junior \& Senior High School at Komaba, University of Tsukuba, 56, 61-67. University of Tsukuba, 56, 61-67.

4) Hara, T., Kinoshita, M. (2018), Possibilities and Challenges of Introducing Digital Textb ooks in Japan, LET Kyushu-0kinawa BULLETIN, 18, 45-56. DOI: 10. 24716/1etko. 18.0_45.

5) Kimihiro Matsunaga (2011), Development and Issues of ICT-Based Education and Learning Sup port ( $\langle$ Feature $\rangle$ Trends in ICT-Based Education and Learning Support), Systems/Control/Informa tion, 5510, 404-411, D0I: 10.11509/isciesci.55.10_404.

6) T. Tachibana, K. Yoshida (2012), Ten years of ICT education, Computers \& Education, 32 3540, DOI:10. 14949/konpyutariyoukyouiku. 32. 35.

7), Fumio Nemoto, Ryoichi Ishitobi, Shigeru Ikuta (2016), Current Status and Issues of ICT E quipment Use in Elementary and Secondary Education, Computers \& Education, 38-43, D0I: 10. 14 949/konpyutariyoukyouiku. 40. 38.

8) Kobayashi, Y., Nakagawa, K., Murai, M., Kawagishi, M., Matsunoh, S., and Shimoda, M. (200 7), A survey on the current status and issue awareness of leaders who promote ICT use in sch ools, Educational Media Research, 141, 49-57, DOI: 10.24458/jaems. 14.1_49.

9) See Standing Committee on General Affairs, Education and Culture (2015), Inspection Repor t, http://www. city. itoshima. 1g. jp/s034/020/030/010/050/13791. pdf, September 29, 2019.

10) Takami Mouri, Yoshio Nakai (2015), Analysis of learners' narratives for composition inst ruction using e-portfolio -Background of learners who did not establish reflection activitie s and challenges of ICT education-, 19th European Symposium on Teaching Japanese as a Foreig n Language, https://www. eaje. See eu/pdfdownload/pdfdownload. php?index=423-424\&filename=72_P oster19_Mouri. Nakai.pdf\&p=bordeaux, September 29, 2019.

11) Iizuka City Committee on Civic and Cultural Affairs (2017), Committee on Civic and Cultu ral Affairs: Achievements and Challenges on Specially Referred Matters, https://www.city.iiz uka. 1g. jp/giji/shise/gikai/kaigiroku/h28nendo/documents/0203 See sibunsiryo1.pdf, September $29,2019$.

12) Urano, H. and Matsunaga, K. (2017), Issues and Prospects for Educational Methods and Curr icula Using ICT: Focusing on the Experiences and Attitudes of University Students Who Wish $t$ o Teach, Bulletin of Saitama Gakuen University, Faculty of Human Sciences, 213-22217. 
13) Toyofuku, Shinpei (2015), Utilization of ICT in elementary and secondary education: 1. W hy is the informatization of school education in Japan stagnating - a shift to learner-cente red ICT utilization -, Information Processing, 564, 316-321.

14) Sasaki, Kyohei (2013), The Importance of ICT Utilization in Education, Research on Life and Welfare: Survey Report of the Meiji Yasuda Institute of Life and Welfare, 85 50-63.

15) Nakanishi, N., Matsumura, S., Arakawa, T. (2014), The Future of Electronic Technology In troduction in School Music Education, Journal of Music Education Practice, 112, 115-125, D0I: 10. 20614/jjomep. 11.2_115.

16) Ministry of Education, Culture, Sports, Science and Technology, Motonobu Toyoshima (201 5), Trends in Information Technology in Education, http://www2. japet. or.jp/seika/pdf/monka_k ichou. pdf, accessed September 29, 2019.

17) See Ministry of Internal Affairs and Communications (2017), Education ICT Guidebook Ver.

1, http://www. soumu. go. jp/main_content/000492552.pdf, 29 September 2019.

18) Hashi, H., Kawabata, H., Eto, T. (2016), Toward the promotion of ICT education, Bulletin of the Research Institute, Momoyama Gakuin University, 42(1), 1-14.

19) Hitoshi Mitomo (2018), Policy and development of ICT utilization promotion in primary an d secondary education in Japan, Asia Pacific Research, 32, 121-140.

20) Yasuyuki Mori (2008), On the educational practice method using ICT, Bulletin of the Univ ersity of Takamatsu. 50128.

21) R. R. Mohanty (2013), ICT advantages and disadvantages, 2013.

22), Satoshi Matsubara, Kentaro Shibusawa, Chikako Kogawa (2014), Issues and Prospects of IC T Education: The First Report of the ICT Education Research Project of the Institute of Cont emporary Social Studies, Toyo University, Contemporary Social Studies, 12 61-72.

23) Tanaka, M. and Shigehiko Toyama(2010). Digital textbooks are unnecessary, Poplar Publish ing.

24) Ministry of Education, Culture, Sports, Science and Technology (2019), Measures to Promo te the Use of Advanced Technology to Support Learning in the New Era (Final Summary), http:/ /www. mext.go. jp/component/a_menu/other/detail/_icsFiles/afieldfile/2019/06/24/ See 1418387 01.pdf, September 29, 2019.

25) Nagaoka, M., Seto, A. (2018), Educational Effectiveness Using ICT, ISFJ Japan Policy Stud ent Conference Policy Forum 2018, http://www. isf j. net/articles/2018/\%E5\%8F\%97\%E8\%B3\%9E\%E8\%A B\%96\%E6\%96\%87/\%E3 \%80\%90\%E6\%85\%B6\%E6\%87\%89\%E7\%BE\%A9\%E5\%A1\%BE\%E5\%A4\%A7\%E5\%AD\%A6\%E3\%80\%91\%E3\%8 0\%90\%E5\%B1\%B1\%E7\%94\%B0\%E7\%AF\%A4\%E8\%A3\%95\%E7\%A0\%94\%E7\%A9 B6\%E4\%BC\%9A\%E3\%80\%91\%E3\%80\%90\%E9\%95\% B7\%E5\%B2\%A1\%E7\%9C\%9F\%E7\%B4\%98\%E3\%80\%91 ( $5 \quad$ 99\%E8\%82\%B2\%E5\%8A\%B9\%E6\%9E\%9C\%E3\%81\%AB\%E3\%81\%A4\%E3\%81\%84\%E3\%81\%A6).pdf, referenced Septemb er 29, 2019.

26) 2012, A study on arithmetic classes using ICT: From the practice in the environment of on e information terminal per person, Mathematics Department, Faculty of Education, Niigata Uni versity, Journal of Mathematics Education, (471), 186-205. 